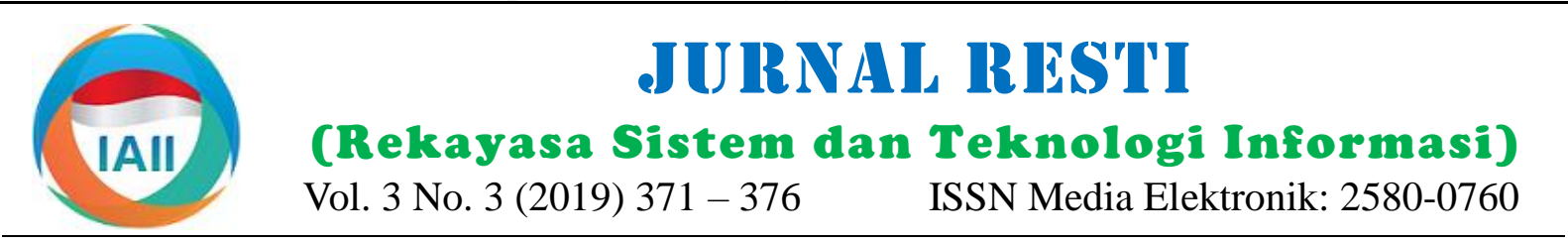

\title{
Performansi Navigasi Robot Leader-Follower menggunakan Algoritma Logika Fuzzy Interval Tipe 2
}

\author{
Gita Fadila Fitriana ${ }^{1}$, Rifki Adhitama ${ }^{2}$ \\ ${ }^{12}$ Prodi Rekayasa Perangkat Lunak, Fakultas Teknologi Industri dan Informatika, Institut Teknologi Telkom Purwokerto \\ '1 gita@ittelkom-pwt.ac.id, ${ }^{2}$ rifki@ittelkom-pwt.ac.id
}

\begin{abstract}
A leader-follower robot is used to perform different tasks without continuous human assistance. The movement of robot leader-follower to environment who do not structure, avoid persecution and achieving goals is very difficult. Related to the problem, the robot leader-follower requires navigating robots independently using Interval Fuzzy Logic Type-2 (IFLT) 2 Algorithm. The IFLT 2 algorithm performance is successfully applied to this leader-follower robot, with 8 base rules less than the Fuzzy Logic Type 1 Algorithm. This simulation, the robot successfully moves to avoid obstacles and go hand in hand with the position of the follower robot always following the position of the robot leader.
\end{abstract}

Keywords: leader follower robot, interval fuzzy logic type-2 algorithm, navigating robots, fuzzy logic type 1 algorithm

\begin{abstract}
Abstrak
Robot leader follower digunakan untuk melakukan tugas yang berbeda tanpa bimbingan manusia secara terus menerus. Pergerakan robot leader follower pada lingkungan yang tidak terstruktur, menghindari halangan dan mencapai tujuan merupakan hal yang sangat sulit. Berkaitan dengan masalah tersebut, robot leader follower memerlukan navigasi robot secara mandiri menggunakan Algoritma Logika Fuzzy Tipe 2 (LFIT) 2. Performansi Algoritma LFIT2 berhasil diterapkan pada robot leader follower ini, dengan 8 basis aturan yang lebih sedikit dari algoritma Logika Fuzzy Tipe 1. Simulasi ini, robot berhasil bergerak dengan menghindari halangan serta berjalan secara beriringan dengan posisi robot follower selalu mengikuti posisi robot leader.
\end{abstract}

Kata kunci: robot leader follower, algoritma logika fuzzy interval tipe 2, navigasi robot, algoritma logika fuzzy tipe 1

(C) 2019 Jurnal RESTI

\section{Pendahuluan}

Navigasi robot secara mandiri untuk memandu pergerakkan sebuah robot di lingkungan yang tidak terstruktur merupakan tugas yang sulit dan menantang [1][2][3]. Navigasi robot dapat bergerak melalui lingkungan untuk mencapai tujuan [4]. Agar robot tidak terganggu atau bertabrakan dengan objek lain, maka diperlukan navigasi dalam menghadapi masalahmasalah ketidakpastian, yaitu ketidakpastian sensor, akuator, dan lingkungan [5].

Robot yang bergerak pada lingkungan yang tidak pasti akan memberikan informasi ke sensor dan mengarah ke berbagai perilaku robot. Beberapa pendekatan untuk kontrol dan strategi pada formasi robot swarm dapat dirujuk pada literatur, seperti pendekatan berbasis prilaku [6][7][8], pendekatan struktur virtual
[9][10][11], pendekatan leader follower [12][3]. Robot leader follower merupakan konsep yang mengikuti pemimpin (leader) didasarkan pada kebutuhan suatu kelompok untuk mencapai keteraturan. Hal terpenting dalam konsep leader follower adalah mengontrol formasi dari robot, sehingga robot dapat mencapai bentuk formasi yang diinginkan [13].

Penelitian yang dilakukan oleh [4], navigasi yang digunakan algoritma logika fuzzy. Penelitian tersebut menjelaskan dengan 16 aturan robot dapat bergerak secara bebas tanpa tujuan. Pada penelitian ini, robot bergerak dengan prilaku leader follower bergerak dalam menghindari halangan dan mencapi target. Algoritma Logika Fuzzy Interval Tipe (LFIT) 2 menggunakan 8 aturan yang dapat menyelesaikan

Diterima Redaksi : 29-07-2019 | Selesai Revisi : 08-08-2019 | Diterbitkan Online : 02-12-2019 
masalah menghindari halangan dan bergerak menuju 2.2. Algoritma Logika Fuzzy Interval Tipe 2 (LFIT) 2 target.

\section{Metode Penelitian}

\subsection{Robot Leader Follower}

Leader follower merupakan salah satu prilaku dari fuzzifikasi merupakan suatu tahapan untuk mengubah robot swarm. Leader follower merupakan robot yang suatu nilai masukan dari bentuk nilai pasti menjadi berperan sebagai robot pemimpin (leader) dan sebagian fuzzy input (variable linguistik). Bentuk variable robot pengikut (follower). Gerak robot follower linguistic disediakan dalam bentuk himpunanmengikuti trajektori robot leader dengan jarak yang himpunan fuzzy dengan fungsi keanggotaannya masingditentukan dalam kecepatan yang stabil serta masing. Fungsi keanggotaan dalam algoritma LFIT 2 percepatan yang dinamis [14].

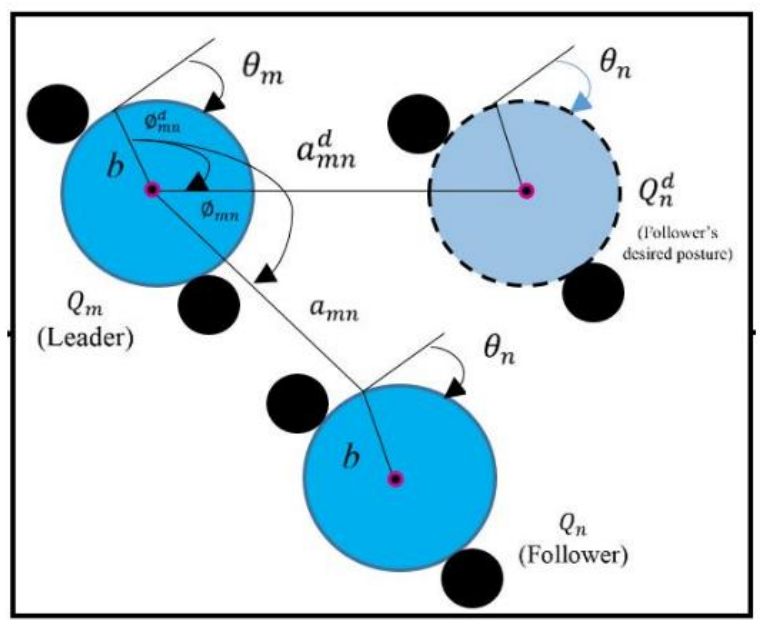

Gambar 1. Robot Leader-Follower [15]

Bentuk persamaan kinematik robot leader follower ditunjukkan pada Persamaan 1 sebagai berikut :

$\dot{Q}_{m}=\left[\begin{array}{c}\dot{x}_{m} \\ \dot{y}_{m} \\ \dot{\theta}_{m}\end{array}\right]=\left[\begin{array}{cc}\cos \theta_{m} & -b \sin \theta_{m} \\ \sin \theta_{m} & b \cos \theta_{m} \\ 0 & 1\end{array}\right]\left[\begin{array}{l}v_{m} \\ \omega_{m}\end{array}\right]$

Dimana $Q_{m}$ merupakan posisi aktual robot leader, $Q_{n}$ merupakan posisi aktual robot follower, $Q_{n}^{d}$ merupakan posisi robot follower yang diharapkan, $a_{m n}$ yaitu jarak actual antar robot leader dan follower, $\phi_{m n}$ merupakan sudut aktual pergerakan roda antara follower dan leader, $a_{m n}^{d}$ merupakan jarak robot leader dan robot follower yang diharapkan, dan $\phi_{m n}^{d} y=\frac{\mathrm{y}_{\mathrm{kiri}}+\mathrm{y}_{\mathrm{kanan}}}{2}$ merupakan sudut pergerakan roda robot leader dan robot follower yang diharapkan. Berdasarkản Persamaan (1) maka dapat diturunkan persamaan rumus kinematik menjadi

$$
\begin{aligned}
& \dot{a}_{m n}=-v_{m} \cos \phi_{m n}+v_{n} \cos \beta_{m n}+b \omega_{n} \sin \beta_{m n} \\
& \dot{\phi}_{m n}=\frac{1}{a_{m n}}\left\{v_{m} \sin \phi_{m n}-v_{n} \sin \beta_{m n}+b \omega_{n} \cos \beta_{m n}\right\}-\omega_{m}
\end{aligned}
$$

\section{(3) 3.1. Lingkungan}

Hasil turunan rumus berupa keluaran kecepatan robot Lingkungan utama dari simulasi dimodelkan sebagai dan perubahan sudut. Nilai ini menjadi keluaran pada algoritma LFIT2. memiliki dua derajat keanggotaan, yaitu derajat keanggotaan primer dan sekunder (yang merupakan derajat keanggotaan dari derajat keanggotaan primer). Sedangkan derajat keanggotaan sekunder dalam algoritma LFT 2 interval adalah bernilai 1, yang disebut FOU (Footprint Of Uncertainty) [17], garis yang berada pada nilai-nilai tertinggi disebut sebagai Upper Membership Function (UMF), dan yang berada pada nilai-nilai terendah disebut sebagai Lower Membership Function (LMF). Fungsi keanggotaan dapat dinyatakan dalam fungsi keanggotaan segitiga, trapesium, sigmoid atau fungsi keanggotaan lainnya. Selanjutnya, tahapan basis kaidah merupakan aturanaturan berupa pernyataan logika fuzzy yang berbentuk "Jika-Maka" (If-Then) yang merupakan inti dari relasi fuzzy [16].

Setelah menentukan basis kaidah pada sistem ini, lalu masuk ke tahapan tipe reduksi. Tipe reduksi merupakan output processing terdiri dari dua langkah. Langkah pertama adalah reduksi tipe (type reduction) dan kedua adalah defuzzifikasi. Hal ini dikarenakan keluaran dari inference merupakan himpunan LFIT2. Metode reduksi tipe bertujuan untuk mengubah himpunan fuzzy tipe 2 yang dihasilkan pada proses sebelumnya menjadi himpunan fuzzy tipe 1. Himpunan yang telah direduksi tipe kemudian didefuzzifikasi menjadi nilai tegas crisp) untuk keluaran dari fuzzy proses [18]. Tahapan terakhir pada algoritma LFIT2 yaitu defuzzifikasi. Defuzzifikasi merupakan Nilai tegas dari suatu himpunan tereduksi dapat dihitung dengan merata-rata nilai paling kanan dan paling kiri dari himpunan tereduksi, atau dapat dinyatakan sebagai:

\section{Hasil dan Pembahasan}

Pada hasil penelitian ini untuk memvisualisasikan suatu benda kehidupan nyata, benda-benda tersebut harus dimodelkan terlebih dahulu. Model-model kemudian digunakan sebagai dasar dari pembuatan perangkat lunak.

bidang dua dimensi, dengan sumbu koordinat $\mathrm{x}$ dan $\mathrm{y}$. 
Arah sumbu x positif dan y positif dari lingkungan Sensor-sensor tersebut kemudian disebut sebagai sensor dapat dilihat pada Gambar 2 berikut

0 , sensor 1, dan sensor 2. Letak dari masing-masing sensor dipisahkan masing-masing sebesar $30^{\circ}$ dari

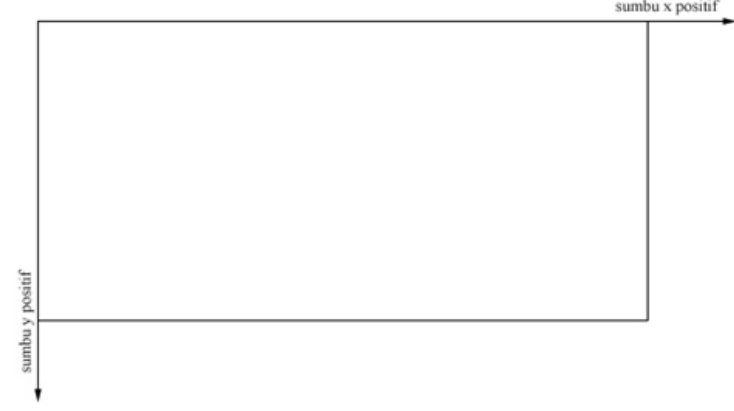

Gambar 2. Model lingkungan simulasi robot

Skala lingkungan adalah 1,4:1 cm, di mana $1 \mathrm{~cm}$ di nyata lingkungan adalah sama dengan 1,4 piksel pada aplikasi. Ukuran pemodelan lingkungan terbentuk ruang 961 x 561 piksel.

\subsection{Pemodelan Robot Leader-Follower}

Robot leader dan robot follower divisualisasikan sebagai bidang lingkaran yang berjalan berdasarkan nilai kecepatan dan sudut yang dapat dilihat pada Persamaan (2) dan (3). Letak model robot swarm leader follower pada lingkungan ditentukan oleh pada keadaan ideal, dimana model sensor akan koordinat titik pusatnya pada lingkungan, yaitu xrobot membaca jarak terdekat dengan halangan yang berada dan yrobot, sedangkan arah robot adalah besar pada juring AO sensor seperti diilustrasikan pada sudutnya terhadap sumbu x positif berupa $\theta$ robot. Besar Gambar 5.

bidang lingkaran ditentukan oleh besar lebar robot, seperti yang diilustrasikan pada Gambar 3 .

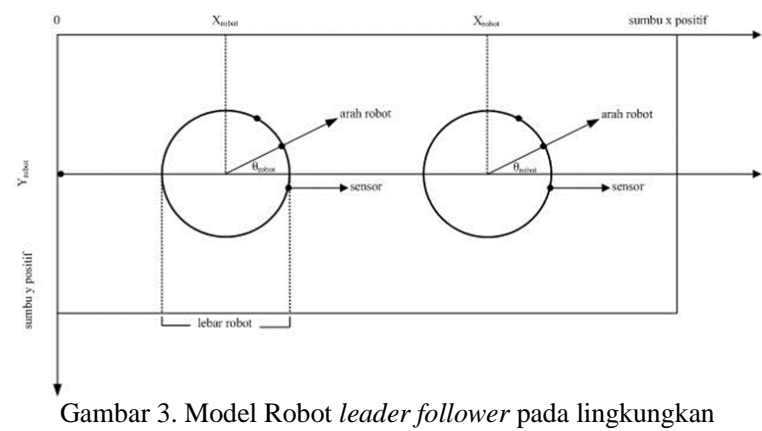

\subsection{Sensor Ultrasonik}

Pada simulasi, model robot swarm memiliki tiga buah model sensor ultrasonik pada bagian depan, samping kiri dan samping kanan, seperti pada Gambar 4.

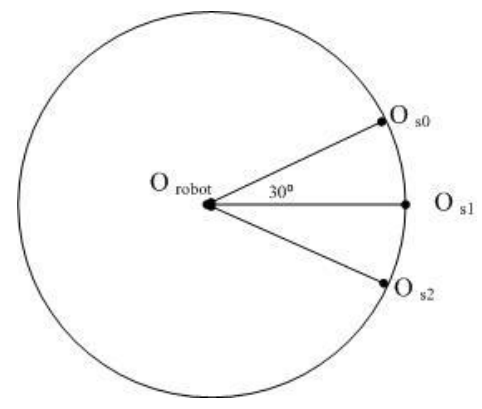

Gambar 4. Letak tiga buah sensor pada robot leader follower

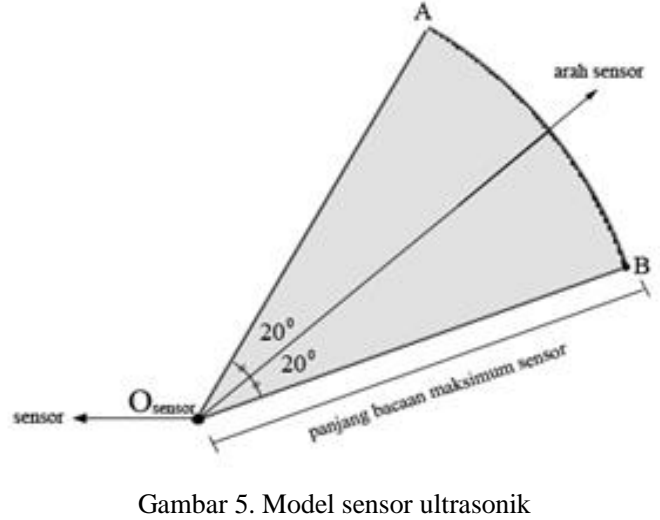

Keadaan ideal pada sebuah sensor ultrasonik adalah nilai besar sudut AosensorB sebesar $400 \mathrm{~cm}$, dan bacaan maksimum, yaitu garis OsensorA dan OsensorB adalah sebesar $300 \mathrm{~cm}$. Pada perangkat lunak ini, hasil bacaan model sensor untuk mendapatkan jarak terdekat antara titik model sensor dengan bidang persegi model halangan.

\subsection{Pengujian Algoritma LFIT2}

Robot leader follower dengan algoritma LFIT2 menggunakan inferensi Mamdani. Menggunakan 2 variabel linguistik. Berikut Tabel 1 kaidah 2 variabel linguistik. 
Gita Fadila Fitriana, Rifki Adhitama

Jurnal RESTI (Rekayasa Sistem dan Teknologi Informasi) Vol . 3 No. 3 (2019) 371 - 376

Tabel 1.Basis Kaidah 2 Variabel Linguistik

\begin{tabular}{|c|c|c|c|c|}
\hline Sensor0 & Sensor1 & Sensor2 & Kecepatan & $\begin{array}{l}\text { Perubahan } \\
\text { Sudut }\end{array}$ \\
\hline Dekat & Dekat & Dekat & Lambat & Lurus \\
\hline Dekat & Dekat & Jauh & Lambat & Kanan \\
\hline Dekat & Jauh & Dekat & Lambat & Lurus \\
\hline Dekat & Jauh & Jauh & Sedang & Kanan \\
\hline Jauh & Dekat & Dekat & Lambat & Kiri \\
\hline Jauh & Dekat & Jauh & Sedang & Kiri \\
\hline Jauh & Jauh & Dekat & Sedang & Kiri \\
\hline Jauh & Jauh & Jauh & Cepat & Lurus \\
\hline
\end{tabular}

Pada sistem navigasi robot leader follower, ditanamkan algoritma LFT 2. Sebuah algoritma Logika Fuzzy dengan keluaran berupa nilai perubahan sudut, dan sebuah lainnya dengan keluaran berupa nilai kecepatan dari robot. Pada pengujian ini robot bergerak secara beriringan dan menghindari halangan berupa lima dinding serta bergerak untuk pencapaian target. Berdasarkan Table 1, seluruh kombinasi kaidah akan dilakukan dengan arah robot adalah 0, yaitu searah dengan sumbu $\mathrm{x}$ dari model lingkungan. Pengujian algoritma LFIT2 menggunakan aplikasi Unity versi 5. Berikut pengujian berdasarkan kombinasi pada Tabel 1.

\section{a. Kombinasi I}

Pada kombinasi I, sensor 0 bernilai dekat, sensor 1 bernilai dekat dan sensor 2 bernilai dekat, sedangkan hasil yang diharapkan adalah model robot berbelok ke kiri. Hasil jalannya model robot pada lingkungan dengan kombinasi ini dapat dilihat pada Gambar 6.

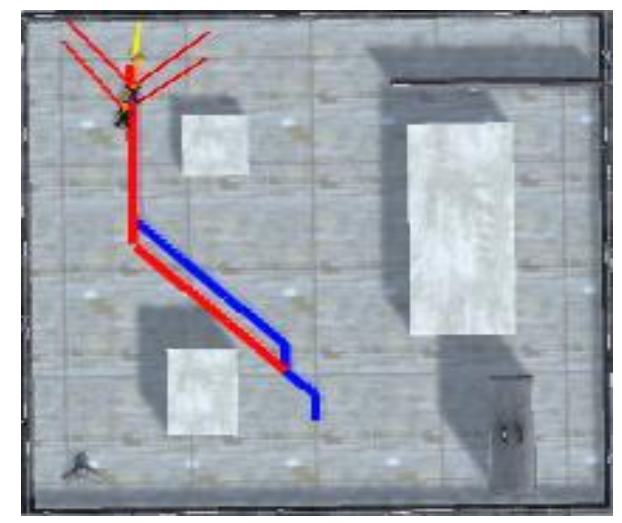

Gambar 6. Lintasan Robot Kombinasi I

b. Kombinasi II

Pada kombinasi II, sensor 0 bernilai dekat, sensor 1 bernilai dekat dan sensor 2 bernilai dekat, sedangkan hasil yang diharapkan adalah model robot berbelok ke kanan. Hasil jalannya model robot pada lingkungan dengan kombinasi ini dapat dilihat pada Gambar 7.

\section{c. Kombinasi III}

Pada kombinasi III, sensor 0 bernilai dekat, sensor 1 bernilai jauh dan sensor 2 bernilai dekat, sedangkan Pada kombinasi V, sensor 0 bernilai jauh, sensor 1 hasil yang diharapkan adalah model robot berjalan bernilai dekat dan sensor 2 bernilai dekat, sedangkan lurus. Hasil jalannya model robot pada lingkungan hasil yang diharapkan adalah model robot berbelok ke dengan kombinasi ini dapat dilihat pada Gambar 8.

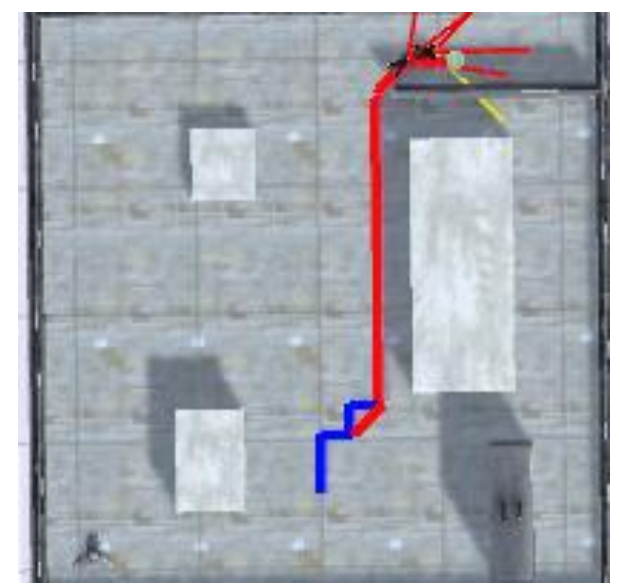

. Gambar 7. Lintasan Robot Kombinasi II

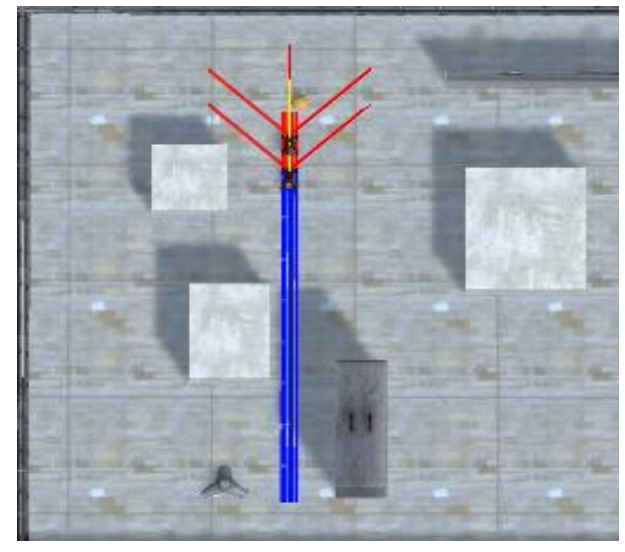

Gambar 8. Lintasan Robot Kombinasi III

\section{d. Kombinasi IV}

Pada kombinasi IV, sensor 0 bernilai dekat, sensor 1 bernilai jauh dan sensor 2 bernilai jauh, sedangkan hasil yang diharapkan adalah model robot berbelok ke kanan. Hasil jalannya model robot pada lingkungan dengan kombinasi ini dapat dilihat pada Gambar 9.

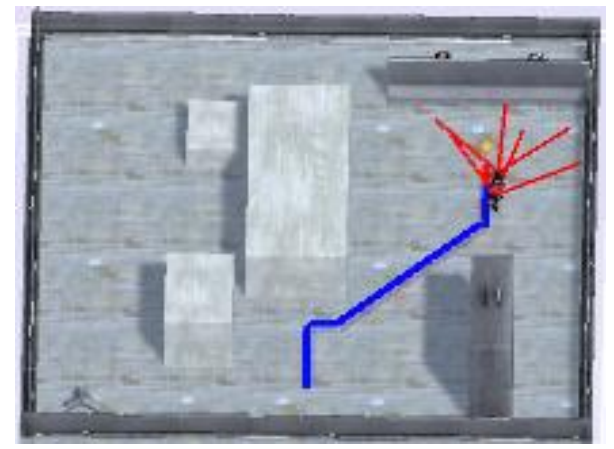

Gambar 9. Lintasan Robot Kombinasi IV

\section{e. Kombinasi V}


kiri. Hasil jalannya model robot pada lingkungan dengan kombinasi ini dapat dilihat pada Gambar 10.

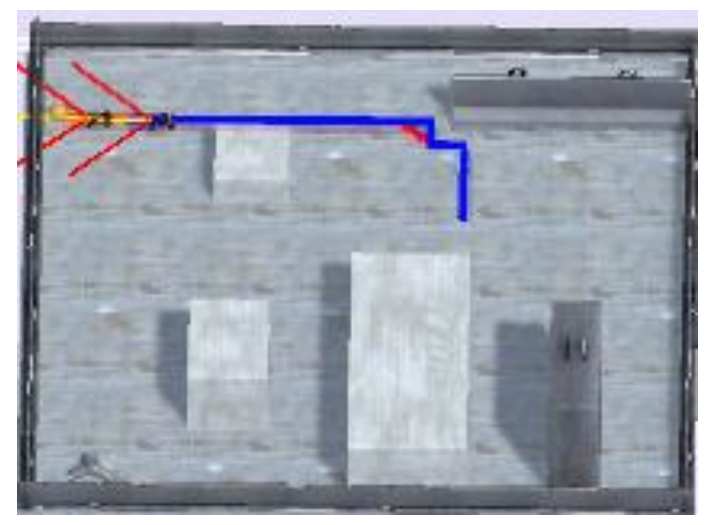

Gambar 10. Lintasan Robot Kombinasi V

\section{f. Kombinasi VI}

Pada kombinasi VI, sensor 0 bernilai jauh, sensor 1 bernilai dekat dan sensor 2 bernilai jauh, sedangkan hasil yang diharapkan adalah model robot berbelok ke kiri. Hasil jalannya model robot pada lingkungan dengan kombinasi ini dapat dilihat pada Gambar 11.

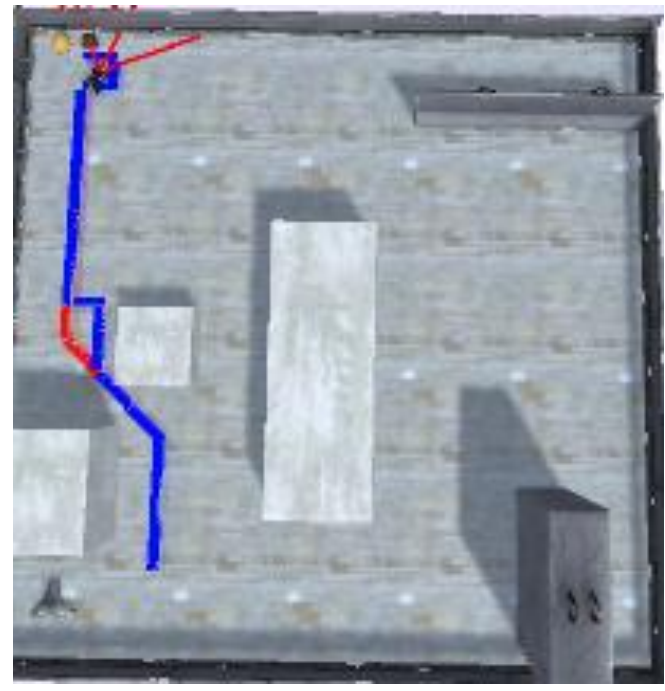

Gambar 11. Lintasan Robot Kombinasi VI

\section{g. Kombinasi VII}

Pada kombinasi VII, sensor 0 bernilai jauh, sensor 1 bernilai jauh dan sensor 2 bernilai dekat, sedangkan hasil yang diharapkan adalah model robot berbelok ke kiri. Hasil jalannya model robot pada lingkungan dengan kombinasi ini dapat dilihat pada Gambar 12.

\section{h. Kombinasi VIII}

Pada kombinasi I, sensor 0 bernilai jauh, sensor 1 bernilai jauh dan sensor 2 bernilai jauh, sedangkan hasil yang diharapkan adalah model robot berjalan lurus. Hasil jalannya model robot pada lingkungan dengan kombinasi ini dapat dilihat pada Gambar 13.

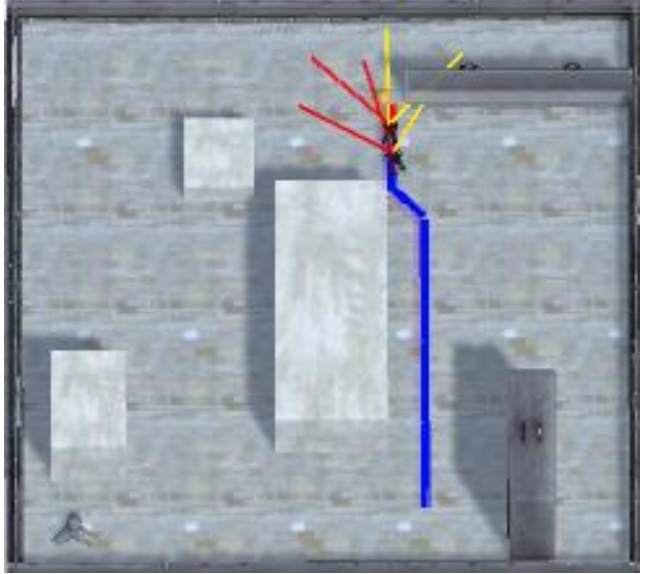

Gambar 12. Lintasan Robot Kombinasi VII

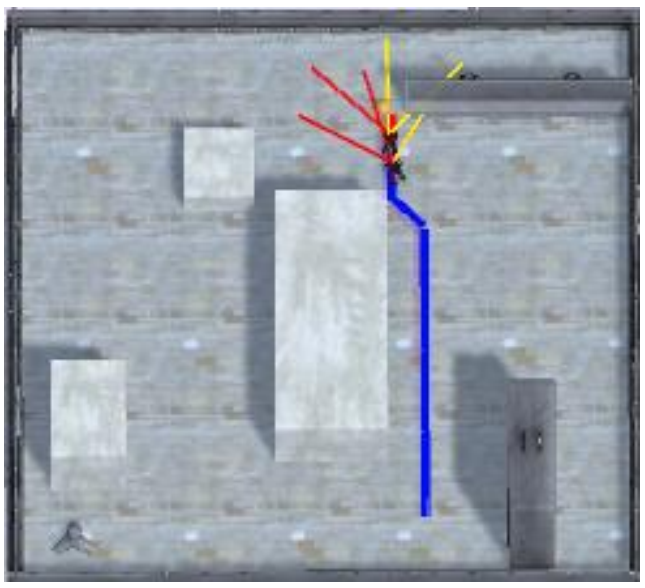

Gambar 13. Lintasan Robot Kombinasi VIII

\section{Kesimpulan}

Penelitian robot leader follower menggunakan navigasi algoritma LFIT2 menghasilkan 8 basis aturan yang dapat berjalan sesuai dengan target tujuan. Pada simulasi ini, robot berhasil bergerak dengan menghindari halangan serta berjalan secara beriringan dengan posisi robot follower selalu mengikuti posisi robot leader. Pada penelitian selanjutnya robot akan ditambahkan 1 robot dengan implementasi secara nyata.

\section{Daftar Rujukan}

[1] A. Saffiotti, "The uses of fuzzy logic in autonomous robot navigation," vol. 1, 1997.

[2] C. Wagner and H. Hagras, "A Genetic Algorithm Based Architecture for Evolving Type-2 Fuzzy Logic Controllers for Real World Autonomous Mobile Robots," 2007 IEEE Int. Fuzzy Syst. Conf., pp. 1-6, 2007.

[3] Z. Li and X. Liu, "Distributed Tracking Control for Linear Multiagent Systems With a Leader of Bounded Unknown Input," vol. 58, no. 2, pp. 518-523, 2013.

[4] S. K. Hussein and M. A. Al-Mutairi, "A Novel Prototype Model for Swarm Mobile Robot Navigation Based Fuzzy Logic Controller," Int. J. Comput. Sci. Inf. Technol., vol. 11, no. 02, pp. 63-77, 2019.

[5] G. F. Fitriana and S. Nurmaini, "Interval Type 2 Fuzzy Logic Algorithm for Leader-Follower Robot." 
Gita Fadila Fitriana, Rifki Adhitama

Jurnal RESTI (Rekayasa Sistem dan Teknologi Informasi) Vol . 3 No. 3 (2019) 371 - 376

[6] T. Balch, R. C. Arkin, and S. Member, "Behavior-Based [13 Formation Control for Multirobot Teams," IEEE Trans. Robot. Autom., vol. 14, no. 6, pp. 926-939, 1998.

[7] J. R. T. Lawton, R. W. Beard, and B. J. Young, "A decentralized approach to formation maneuvers," IEEE Trans. Robot. Autom., vol. 19, no. 6, pp. 933-941, 2003.

[8] A. Brunete, M. Hernando, E. Gambao, and J. E. Torres, "A behaviour-based control architecture for heterogeneous modular," Rob. Auton. Syst., vol. 60, pp. 1607-1624, 2012.

[9] K. Tan and M. A. Lewis, "Virtual Structures for HighPrecision Cooperative Mobile Robotic Control *," Proc IROS 96 IEEE, pp. 132-139, 1996.

[10] M. A. Lewis and K. Tan, "High Precision Formation Control of Mobile Robots Using Virtual Structures," Auton. Robot. 4, vol. 403, pp. 387-403, 1997.

[11] J. P. Desai, J. P. Ostrowski, and V. Kumar, "Modeling and [ control of formations of nonholonomic mobile robots," Robot. Autom. IEEE Trans., vol. 17, no. 6, pp. 905-908, 2001.

[12] J. L. Whittington and R. G. Bell, "Leader - member exchange, enriched jobs, and goal-setting: Applying fuzzy set methodology," J. Bus. Res., vol. 69, no. 4, pp. 1401-1406, 2016.
13] J. D. McLurkin, "Analysis and Implementation of Distributed Algorithms for Multi-Robot Systems," Theses Diss., 2008.

[14] P. Chandak, "Study and Implementation of "Follow the Leader," 2002.

[15] B. Tutuko, S. Nurmaini, Saparudin, and G. F. Fitriana, "Enhancement of Non-Holonomic leader-follower formation using Interval Type-2 Fuzzy Logic Controller," Int. J. Online Eng., vol. 14, no. 9, pp. 124-142, 2018.

[16] L. Hakim and V. Yonatan, "Deteksi Kebocoran Gas LPG menggunakan Detektor Arduino dengan algoritma Fuzzy Logic Mandani," J. RESTI (Rekayasa Sist. dan Teknol. Informasi), vol. 1, no. 2, p. 114, 2017.

17] Q. Liang and J. M. Mendel, "Interval Type-2 Fuzzy Logic Systems : Theory and Design," IEEE Trans. Fuzzy Syst., vol. 8 , no. 5 october, pp. 535-550, 2000.

[18] N. H. Seng, "Implementation of Various Types of Fuzzy Controls on a Mobile Robot Using Sonar Sensors," 2008. 